\title{
Representación territorial y democracia
}

\author{
Diego Reynoso*
}

\begin{abstract}
The political weight of the Latin-American territories is clear from their electoral processes, administrative organization and party systems with 'low nationalization' (Mainwaring and Jones, 2003). Argentina, Bolivia, Brazil, Colombia, Chile and Ecuador, among others, are a proof of the role of territory in their legislative representation. Bicameral systems turn out to be a solution to the democratic representation problem when both, territory and citizens are important. In this article, we explore the normative tension between the representation principle of "one person, one vote" and the principle of territorial equality that exists (not only) in federal systems. We also present an analysis of the bicameral representation systems following the above mentioned criteria. The majority of the literature -with some exceptions (e.g. Kymlica, 1996)-in one way or another has condemned the existence of territorial criteria. This point is also addressed in this work.
\end{abstract}

Keywords: territorial representation, bicameralism, malapportionment, electoral districts.

\section{Resumen}

El peso político de los territorios en América Latina se manifiesta a través de sus sistemas electorales, de su organización administrativa y de sus sistemas de partido con 'baja nacionalización' (Mainwaring y Jones, 2003). Argentina, Bolivia, Brasil, Colombia, Chile, Ecuador, entre otros son una prueba del papel de los territorios en su sistema de representación legislativa. Los sistemas bicamerales permiten hacer frente al dilema de la representación democrática cuando los territorios, además de los ciudadanos, importan. En este trabajo, se explora la tensión normativa entre el principio 'una persona, un voto' de representación y el principio de representación de igualdad territorial existente (no sólo) en los sistemas federales. Además, se presenta un análisis de los sistemas de representación bicameral conforme a estos dos criterios. Salvo excepciones (por ejemplo, Kymlica, 1996), la mayoría de la literatura previa, de una forma u otra ha juzgado patológica la existencia de criterios territoriales. En este trabajo se discute esa apreciación.

Palabras clave: representación territorial, bicameralismo, sobre-representación distrital, distritos electorales.

* Facultad Latinoamericana de Ciencias Sociales, Sede México: Correo-e: diegorey@flacso.edu.mx 


\section{Democracia y representación de las preferencias}

Según Dahl (1989: 131-145) un orden político se considera democrático cuando se cumplen dos premisas básicas: i) que cada miembro tenga el derecho a ser tratado y considerado en pie de igualdad con los demás (igualdad intrínseca) y ii) que en el momento de tomar las decisiones, las opiniones de todos los ciudadanos respecto de la conveniencia de tomar tal o cual decisión sean igualmente válidas (igualdad categórica). ${ }^{1}$ La primera premisa remite al principio elemental de ciudadanía; es decir, que todos sean iguales políticamente, más allá de cualquier característica particular: etnia, religión, lengua, género, clase o región. La ciudadanía supone que el orden político -y toda su materialización legal e institucional- es ciega a las particularidades y se apoya en la universalidad de la persona.

La segunda premisa supone que en el proceso de toma de decisión de los asuntos comunes se satisfaga el principio 'una persona, un voto'. En otras palabras, que ninguna voz tenga peso diferente en la determinación de las decisiones sobre los asuntos comunes. Así, por ejemplo, se ha definido "la democracia como el simple gobierno de la mayoría, con base en el principio de 'una persona, un voto'” (Elster, 1988: 33). Esto supone que el contexto apropiado para la construcción de un conjunto de reglas que permitan el gobierno democrático, sólo es posible si la asociación política considera que todos sus miembros están igualmente cualificados para decidir sobre el gobierno del grupo. Ello significa que todos los miembros "deben ser considerados políticamente iguales" (Dahl, 1989: 47), lo que nos lleva directamente a considerar que las preferencias de los ciudadanos deben ser contabilizadas en forma igual, sin ningún tipo de distinción o ponderación (Dahl, 1971; 14).

En la literatura sobre democracia proveniente de la teoría de la elección social, la igualdad del voto aparece como una de las condiciones mínimas para la elección social democrática. Por ejemplo, el teorema de la imposibilidad de Arrow (1951) arriba a la sorprendente conclusión de que ningún método de elección puede cumplir con la exigencia de cuatro criterios normativos míni-

${ }^{1}$ A decir de Riker (1982: 4-8) cualquier definición o interpretación de democracia incluye tres elementos o propiedades básicas: participación, libertad e igualdad. La cuestión central reside, en todo caso, en la relación que existe entre los medios para alcanzar los fines del orden democrático justo y el papel otorgado a la elección como medio esencial de la democracia. 
mos: admisibilidad universal, unanimidad u optimalidad de Pareto, independencia de las alternativas irrelevantes y no-dictadura. ${ }^{2}$ Es decir, que ningún método de votación -o de agregación de preferencias individuales- puede satisfacer simultáneamente estas condiciones elementales de justicia y producir, al mismo tiempo, decisiones sociales lógicamente coherentes (Riker, 1982: 115). El contenido de este teorema ha sido revisado por muchas otras obras (por ejemplo Black, 1958 y Sen 1970). Aquí quisiera considerar tan sólo dos de las condiciones: la de unanimidad u optimalidad de Pareto y la de no-dictadura. En el caso de la sobre-representación distrital ambas condiciones pueden estar violándose.

Supongamos dos conjuntos de ciudadanos c1 y c2, tal que $\mathrm{c} 1>\mathrm{C} 2$; y que para $\mathrm{c} 1$ la opción $\mathrm{x}>\mathrm{z}$ y que para $\mathrm{C} 2 \mathrm{z}>\mathrm{x}$, se sigue vía la condición de unanimidad que la elección social debería ser la opción ' $x$ '. Ahora bien, si la decisión social fuera ' $z$ ' entonces las preferencias de $\mathrm{c} 1$ son irrelevantes, debido a que c2 funge como dictador, en términos de Arrow. Por lo tanto, si todos somos iguales, cada preferencia debería pesar lo mismo bajo un método de cómputo cualquiera para arribar a una decisión social. Si ello no es así, entonces el resultado está distorsionado. La sobre-representación distrital introduciría un problema de este tipo bajo la perspectiva de la teoría de la elección social.

Hasta aquí ningún problema. Todos somos iguales ante el orden político, y lo que es aún de mayor centralidad: todos tenemos el mismo peso en la toma de decisiones acerca de los asuntos comunes, como por ejemplo puede ser la elección de los representantes que tomaran esas decisiones.

Pero es justamente ahí donde aparece el problema. Este sentido numérico igualitario que contiene el ideal democrático parece no cumplirse, ni siquiera formalmente en las democracias contemporáneas. Resulta sumamente curioso que en muchos regímenes democráticos se organiza la representación legislativa -es decir la selección de los representantes- con niveles muy elevados de sobre-representación distrital. Esto es, que algunos distritos tienen un porcentaje de escaños mayor que el porcentaje de población que reside en los mismos, lo cual puede llevar a situacio-

\footnotetext{
${ }^{2}$ No voy a hacer aquí una descripción y una definición de lo que cada una de estas condiciones representa o significa. Existe una exhaustiva bibliografía en donde se reproduce hasta el hartazgo la explicación del teorema de Arrow, incluido claro está el mismo trabajo seminal de Arrow (1951). Puede consultarse al respecto Riker (1982: 115-136), Shepsle y Bonchek (1997), Hinich y Munger (1997), entre otras numerosisimas obras pertencientes a esta tradición.
} 
nes como las descrita formalmente respecto de los dos conjuntos de ciudadanos. Veamos algunos ejemplos en América Latina.

Colombia: en las elecciones de 1998 y 2002 en el distrito electoral de Bogotá se eligeron 18 escaños, de un total de 161 que componen la cámara de representantes. ${ }^{3}$ Esos 18 escaños representan $11.18 \%$ del total, mientras que en ese distrito se encuentra aproximadamente el 16\% del electorado colombiano. ${ }^{4}$

Argentina: desde las elecciones de 1993 en adelante la provincia de Buenos Aires reúne a un total aproximado de 37\% de la población electoral de todo el país y sólo elige unos 70 escaños (35 en cada elección por mitades) de un total de 257, lo que representa $27 \%$ de los escaños. De este modo, Buenos Aires tiene una sub-representación de aproximadamente $10 \%$.

Brasil: en igual situación que Buenos Aires se encuentra Sao Paulo. Por población le corresponderían unos 113 escaños de un total de 513 que integran la cámara baja, pero por tope constitucional a Sao Paulo sólo se le asignan 70 escaños de los 513, según datos de 1994.

Esta cuestión merece mayor atención de la que en escasamente se la ha otorgado. Sin lugar a dudas las preferencias de algunos ciudadanos están ponderadas y sobre-representadas mientras que las preferencias políticas de otros están sub-representada en las legislaturas. Ello pone sobre la mesa el hecho de que la sobrerepresentación, tal y cómo se presenta, y la representación democrática, están en tensión.

Sin embargo, es necesario poner en perspectiva porqué en algunas sociedades se produce esto. Conviene definir qué constituye la unidad de representación, o en otras palabras: qué se representa. Esa cuestión es aún más relevante en sociedades complejas y heterogéneas (Elazar, 1987; Lijphart, 1999), en estados plurinacionales (Linz, 1997; Fossas y Requejo, 1999), y en aquellos atravesados por diferencias lingüísticas, étnicas, religiosas y territoriales (Kymlica, 1996). La representación de estas particularidades necesariamente vincula dos dimensiones institucionales, que a esta altura resultan claves: la organización territorial del Estado y la estructura legislativa. ${ }^{5}$

${ }^{3}$ No cuento aquí los cinco escaños de las representaciones especiales.

${ }^{4}$ Siguiendo un criterio de representación sin sub o sobre-representación a este distrito le corresponderían aproximadamente unos 26 escaños.

${ }^{5}$ La cuestión aquí es sobre qué se representa, por lo que las dimensiones institucionales relevantes son federalismo-unitarismo y unicameralismo-bicameralismo. La cuestión sobre cómo se representa aquello que hay que representar nos lleva directo al sistema electoral y al principio de representación, problema que se analizará más adelante. 


\subsection{Acerca del principio 'una persona, un voto'}

El principio de que cada voto de cada ciudadano se cuente como uno, y solo uno, parece ser el criterio mínimo de igualdad electoral democrática (Elster, 1988). Este principio puede rastrearse en los orígenes de la Revolución Francesa. Uno de los grandes logros revolucionarios de 1789 fue, justamente, que el voto de cada representante de cada estamento contara igual (Sartori, 1992: 230); en palabras de Danton diríamos "un voto por cabeza". Antes de esa conquista cada orden o Estado contaban cada una con un voto, lo que producía la sistemática derrota del tercer Estado y el triunfo de las preferencias de los nobles y el clero (a pesar de que el tercer Estado era el más multitudinario). Podría decirse que en la época revolucionaria existía una disputa representativa que tenía en el centro la cuestión de la sobre-representación.

La igualdad del voto, entonces, tiene su fundamento democrático en la idea de que todos cuenten igual sin ningún tipo de distinción y privilegio. Para Dahl, "todo miembro debe tener una igual y efectiva oportunidad de votar, y todos los votos deben contarse como iguales" (Dahl, 1989: 48). ${ }^{6}$ De este modo el argumento es pertinente a los efectos de evaluar de qué forma se distribuye la representación política, es decir cuál es el criterio de distribución de los escaños de la legislatura nacional (o multinacional) entre los distritos o sub-unidades. Dependiendo de cómo se tracen los límites de los distritos electorales y cómo se distribuyan los escaños que le corresponde a cada uno, los sistemas electorales se pueden desviar o acercar al criterio dabliano de la igualdad del voto. Por ejemplo, si no se adjudican los escaños que corresponden a un distrito según el tamaño de su población, entonces no existe una igualdad en los electorados, de tal manera que algunos tienen un mayor peso o influencia con su voto en la elección de los representantes. De este modo, el voto de los ciudadanos se cuenta en forma desigual.

Las desigualdades en el peso del voto pueden producirse en la simple y sencilla tarea -aunque no inocente- de adjudicar los escaños a los distritos. En otras palabras, la distorsión puede ser

\footnotetext{
${ }^{6}$ Por otra parte, en el artículo 21, inciso 3, de la Declaración Universal de los Derechos Humanos, 1948-1998 (Naciones Unidas, 2003), se afirma este ideal como un pilar de los derechos humanos, señalando que "la voluntad del pueblo es la base de la autoridad del poder público; esta voluntad se expresará mediante elecciones auténticas que habrán de celebrarse periódicamente, por sufragio universal e igual y por voto secreto u otro procedimiento equivalente que garantice la libertad del voto".
} 
una función del criterio de representación que se adopte y de la forma en que se establezca la representación que le corresponde a cada una de las divisiones territoriales de un país, allí donde existan. Este aspecto normativo de la igualdad del voto se traduce en términos prácticos en el trazado de distritos; al respecto Monroe señala que "voter equality demands that we divide the electorate into $m$ segments of equal size $(\mathrm{n} / \mathrm{m})$ and assign a candidate to each segment" (Monroe, 1995: 931).

Casi todos los países del mundo dividen el territorio en diferentes distritos como unidad de elección de los cargos legislativos, ${ }^{7} \mathrm{de}$ modo tal que si se cumpliera el criterio de la igualdad, entonces le correspondería a cada distrito un porcentaje de escaños legislativos equivalentes al porcentaje de electores existentes en cada uno de esos distritos. En esa línea de argumentación, Balinski y Young (1983) sostienen que el ideal 'una persona, un voto' implica que nadie tenga una voz mayor que otro en la elección y conformación de los cuerpos legislativos, pero lo cierto es que "en las democracias representativas este ideal es difícil de encontrar".

En algunos sistemas políticos, y muy frecuentemente en los sistemas federales, existe algún grado de desviación del principio democrático de la igualdad del voto, y no por ello han dejado de ser democráticos. De hecho han logrado sobrevivir unidos, mantenerse juntos gracias a la existencia de sobre-representación de las preferencias minoritarias (Kymlica, 1996). ${ }^{8}$ La igualdad del voto se topa a menudo con la heterogeneidad social o con el desarrollo desigual de las regiones. En algunos países, una distribución de la representación entre los distritos conforme al número de sus electorados convertiría a la política nacional en la política de las grandes metrópolis o en la política del centro, quedando las áreas periféricas, menos pobladas y generalmente rurales, al margen de las decisiones nacionales. ${ }^{9}$ Incluso algunos grupos sociales

7 "Nearly all national assemblies are elected using geographic districts" (Monroe, 1995: 933). Obviamente que hay excepciones, pero estas son pocas. Por ejemplo, Holanda, Israel, Namibia, Perú y Sierra Leona en sus cámaras bajas utilizan un solo distrito electoral y no dividen el país en distritos; mientras que Holanda, Colombia, Paraguay y Uruguay utilizan esa misma modalidad distrital en sus cámaras altas.

${ }^{8}$ En ciudadanía multicultural, Kymlica dedica un capítulo entero a reflexionar sobre la necesidad de darle voz a las minorías y a criticar duramente la representación con base en criterios puramente proporcionales a la hora de considerar la representación para los grupos en desventaja.

${ }^{9}$ Durante los primeros pasos y bosquejos de esta investigación, a propósito de una presentación en la Universidad de Salamanca, un colega señaló el problema de repartir según la población en el caso de Costa Rica. El argumento puede ser extendido a otras situaciones en las que las disparidades económicas, étnicas, sociales, culturales, lingüís- 
diferentes o que constituyen una minoría dentro del Estado pueden quedar completamente subordinados a las decisiones del grupo mayoritario. En países con profundas diferencias territoriales, aunque sean socialmente homogéneos, la arrolladora presencia de algunas regiones en detrimento de otras es una de las causas que puede legitimar una medida correctiva que derive en ponderar el peso de la representación y abandonar el criterio de representación conforme a 'una persona un voto' o criterio demo-orientado. ¿Hasta dónde el principio 'una persona, un voto' debe ser tolerado? O mejor dicho ¿Cuánto desvío del principio se puede tolerar? ${ }^{10}$

\subsection{Acerca de la igualdad territorial}

Los Federalistas (1780) pensaron la igualdad de representación de los Estados en el senado como un reconocimiento a la soberanía de los mismos, pero a su vez "como protección contra las leyes inconvenientes, contra el achaque del espíritu de partido...”, y para evitar que los estados grandes en población dominen a los pequeños. En ese sentido, el espíritu que está detrás de la adopción del criterio de representación territorial expresa la necesidad de un contrapeso institucional contra la tiranía de la mayoría y un resguardo para los derechos de las minorías. La justificación del criterio de representación territorial del federalismo moderno se encuentra en los orígenes de los debates de la constitución federal de los Estados Unidos, que se plasma en la adopción de un sistema bicameral como mecanismo institucional de frenos y contrapesos (checks and balances).

La existencia de instituciones bicamerales, o cuerpos deliberativos separados, es mucho más vieja que la creación del moderno federalismo americano (Tsebelis y Money, 1999: 15-29). En efecto, el bicameralismo fue puesto en marcha primero en los Estados unitarios como método de representación de las clases sociales (Tsebelis y Money, 1999: 6). La adopción del criterio de representación territorial se expandió en muchos sistemas políticos, no sólo federales, dando lugar a la representación de las sub-unidades territoriales en forma igualitaria, lo que trajo aparejado otra

ticas o territoriales no posean un mecanismo de compensación político, como el caso de los senados en los países federales.

${ }^{10}$ Para algunos, "the deviation from the one citizen-one vote principle that federalism necessary implies may be seen as a violation of the principle of equality" (Stepan, 1999: 23). 
modalidad constitutiva de las instituciones bicamerales. El dilema de la adopción de diferentes criterios de representación se resuelve en los sistemas federales adoptando un formato bicameral que puede dar lugar al criterio demo-orientado en la cámara baja, y al criterio territorial (o terra-orientado) en la cámara alta (Balinski y Young, 1983:9). Pero contrariamente a la asociación que se observa actualmente entre bicameralismo y federalismo, los sistemas federales fueron en sus orígenes unicamerales (Tsebelis y Money, 1999: 31-32), mientras que los sistemas unitarios eran originalmente bicamerales, adoptando criterios de representación de clase (Tsebelis y Money, 1999: 29-31) en lugar de un criterio territorial o un criterio demo-orientado.

En la actualidad, el poder legislativo nacional, federal o de la unión admite una cámara de representación en donde las subunidades se encuentran representadas bajo un criterio de reconocimiento de igualdad como una instancia en donde se expresa la unión de las sub-unidades (Elazar, 1987: 45 y 58). En general, son los senados o cámaras altas las que se componen mediante un criterio territorial de representación igualitaria. Con esta equitativa forma de distribución territorial de la representación de la cámara alta, y con las especiales atribuciones de esta cámara, que varían de país en país (véase Stepan, 1999: 28 y Tsebelis y Money, 1999: 48-52), la política nacional se convierte en la arena de todas las sub-unidades, independientemente de su población, su riqueza o su extensión.

Paradójicamente, los criterios demo-orientado y terra-orientado, se trasformaron casi exclusivamente en el patrón adoptado por los sistemas federales con la expansión del republicanismo democrático en estructuras bicamerales. Ambos criterios parecen haber evolucionado juntos y al mismo tiempo parecen ser la huella distintiva de la representación moderna, aboliendo las distinciones de clase o estamento, dando lugar a los modernos sistemas federales democráticos. De este modo, la transformación de los sistemas federales unicamerales en sistemas bicamerales, al parecer con la aparición del modelo estadounidense, ha influido en el desarrollo paralelo de ambos criterios de representación, destinados cada uno a ser el criterio de cada cámara (Tsebelis y Money, 1999). El dilema de representación conforme al ideal 'una persona, un voto' en los casos unicamerales es de difícil solución, puesto que la cámara debe representar tanto a los ciudadanos en forma igualitaria, como equilibrar las representaciones regionales, provinciales o estaduales -en el caso de que éstas supongan una 
diferencia política en el mismo cuerpo legislativo-, tal es el caso de los sistemas unitarios con altos grados de descentralización (Linz, 1997).

Obviamente, los sistemas federales no responden a un único modelo de organización territorial (véase Elazar, 1987; Linz, 1997 y Stepan, 1999). Pero el modelo aparentemente más extendido es el de una combinación entre el principio 'una persona, un voto' y el criterio de igualdad de representación de las sub-unidades mediante la adopción de un sistema bicameral. En una de las cámaras se expresa la representación igualitaria y diferenciada de las sub-unidades políticas, mientras que en la otra los ciudadanos están representados como miembros de la unidad política mayor sin distinción.

\section{Democracia y bicameralismo}

Si se toma como referencia la distribución de los escaños a través de los distritos, el ideal normativo se inclina hacia lo que denomino un criterio demo-orientado, esto es que los escaños se asignen proporcionalmente a la población o al número de votantes de cada distrito electoral o sub-unidad. De este modo, se garantiza que ninguna preferencia esté sub-valuada o sobre-dimensionada en la legislatura. Por el contrario, en los sistemas federales la representación se inclina hacia un criterio terra-orientado, el cual, generalmente toma la forma de una igualdad representativa entre las sub-unidades -estados, provincias, länders, cantones, etc.-. La igualdad de representación territorial tiene cabida en la adopción de un sistema bicameral. Linz (1997) identificó este hecho como una característica de los sistemas federales: esto es, la existencia de una segunda cámara en el ámbito del Estado que representa a las sub-unidades federales en forma igualitaria y que no representa a sus poblaciones o electorados.

Los Estados cuya organización es democrática y federal tienen que intentar combinar dos criterios de representación muy diferentes para que tanto democracia como federalismo no estén representativamente debilitados. Mientras que el criterio demoorientado supone un voto per capita, el criterio terra-orientado supone igualdad de representación para cada sub-unidad o, para hacerlo más contrastante, un voto por sub-unidad. Por tal motivo, los sistemas federales democráticos poseen en su amplia ma- 
yoría una estructura legislativa bicameral. ${ }^{11}$ A pesar de que el criterio territorial es un criterio legítimo de representación del sistema federal, sigue existiendo una creencia común pro-igualitaria del voto que hace más hincapié en la justicia del criterio demo-orientado.

\subsection{Incongruencia y asimetrías}

Cuando existen dos criterios de representación se produce lo que Lijphart denominó bicameralismo incongruente (Lijphart, 1999). La incongruencia aumenta la probabilidad de que se produzcan dos mayorías partidarias diferentes, una en cada cámara. Los miembros de la cámara territorial representan a las preferencias partidarias de la mayoría existente en cada una de las sub-unidades. Pero dependiendo de la distribución demográfica y de la distribución territorial del voto, la conformación total de la cámara territorial puede producir dos resultados representativos problemáticos en términos democráticos igualitarios: i) excluir las preferencias de las minorías de cada sub-unidad, además de ii) no ser la expresión de la mayoría de los ciudadanos de todo el Estado federal.

El resultado i) puede ser minimizado con una pequeña cuota de representación minoritaria, dejando la representación mayoritaria a la mayoría o a la primera minoría. Este punto es crucial, debido a que a medida de que la competencia se incrementa en un sistema político (ya sea el Estado federal o una sub-unidad) es muy difícil encontrar mayorías, esto es, 50\% más uno de los votos. Antes bien, la representación mayoritaria suele quedar en manos de la primer minoría. En cambio el resultado ii) sólo se puede evitar abandonando el criterio terra-orientado e instaurando un sistema proporcional a escala nacional o distribuyendo los escaños conforme a un criterio demo-orientado. Pero es evidente que esta solución va en contra del criterio federal de igualdad entre las sub-unidades. En este sentido, no es un resultado que respete el sentido democrático de una elección, en tanto que no expresa las preferencias de la mayoría de todos los ciudadanos del Estado, sino que representa la suma de las preferencias de las mayorías de las sub-unidades. ${ }^{12}$ Pero de esto se trata el control

\footnotetext{
${ }^{11}$ A modo de corroboración, de los 15 estados federales democráticos existentes en la actualidad, todos ellos poseen una estructura legislativa bicameral. La única excepción es la Unión Europea si -como creo que así es- se la considera un sistema federal.

${ }^{12}$ Por citar un ejemplo que ha llamado la atención del mundo, en Estados Unidos, la democracia existente más antigua del planeta, prima este principio en la elección presi-
} 
federal, el pacto entre Estados soberanos e iguales. De allí la idea de mayoría compuesta como expresión no de la simple suma de individuos, sino de grupos complejos (Elazar, 1987). De todos modos, en las cámaras territoriales pueden estar representadas mayorías que paradójicamente no coinciden con la mayoría de los ciudadanos de todo el Estado. Por ello, si la cámara baja se constituye mediante el criterio de representación demo-orientado, puede darse la situación en que existan dos mayorías legislativas diferentes. El dilema institucional que esto supone se expresa en el resultado de la representación y, por lo tanto, repercute en el proceso de construcción de la política pública.

\section{El arte de combinar criterios de representación}

Los regímenes democráticos pueden adoptar diferentes formas de ordenar y armonizar la representación, y muy pocas veces ésta se logra mediante un solo criterio representativo. La representación democrática presupone el principio 'una persona, un voto', y ello implica la asignación de representación a los diferentes distritos electorales o sub-unidades de acuerdo con el número de ciudadanos existente en cada uno de ellos, de manera tal que no haya ninguna ponderación de las preferencias. En este sentido, normativamente sobre-representación distrital y democracia son irreconciliables.

En cambio, el criterio de representación territorial supone otro tipo de igualdad: una igualdad territorial o entre las partes o grupos que componen el Estado, lo cual necesariamente implica sobre-representación. Bajo la perspectiva de simetría o relativa simetría representativa entre las sub-unidades -que bien puede ser una forma de compensación de las disparidades existentes en términos políticos, poblacionales o económicos- la sobre-representación distrital puede ser un mecanismo complementario y a veces necesario para el funcionamiento del régimen democrático.

Las sub-unidades que componen un Estado pueden ser territorios (federalismo) o grupos étnicos, lingüísticos, etc. (consorcionalismo). La forma más sencilla de sobre-representación dis-

dencial. El presidente de los Estados Unidos de América no resulta de la mayoría de las preferencias de los ciudadanos, sino de la mayoría de las preferencias existentes en cada sub-unidad federada. El colegio electoral cumple la función de cámara de representación de las preferencias de las mayorías de cada uno de los estados. En la elección presidencial del 2000, el triunfo de George W. Bush se debió al mecanismo citado. Si el presidente fuera electo por la suma de las preferencias de los ciudadanos de todo el Estado, entonces la victoria hubiese sido del candidato demócrata Al Gore. 
trital es asignar igual representación a cada sub-unidad territorial, como ocurre en algunos senados de sistemas federales como Estados Unidos, México, Brasil y Argentina. También existe la posibilidad de compensar con un plus mínimo de representación según el tamaño de la sub-unidad como los senados de Alemania, Austria o España. Otra forma territorial de sobre-representación distrital es la existencia de mínimos de representación, como por ejemplo las cámaras bajas de Argentina, Brasil, España entre otros. Visto desde una perspectiva individualista de la composición del Estado-nación, es decir que éste está compuesto de individuos iguales ante el mismo y entre sí, la sobre-representación distrital como compensación representativa aparece como una irritación normativa en torno a la organización de la representación democrática. No obstante, allí donde las diferencias entre las diversas partes que componen la sociedad se reconocen como tales es difícil partir de la perspectiva de que el Estado está compuesto por individuos iguales entre sí.

\subsection{Bicameralismo y sobre-representación}

Institucionalmente hablando la representación política está condicionada, entre otras cosas, por la estructura legislativa y por la forma de distribuir los escaños a través de los distritos, es decir, por los criterios de representación (territoriales o demográficos). La combinación de ambas reglas es una expresión de la complejidad subyacente al sistema político. En este sentido, los sistemas bicamerales son más complejos que los unicamerales, y por lo general necesitan de una doble articulación de la representación política. Las cámaras bajas suelen ser las cámaras demo-orientadas, o las "one person-one vote chamber" (Stepan, 1999). Mientras que las cámaras altas o senados suelen poseer un mismo número de escaños por distrito. Tal es el caso de Argentina y Brasil, que asignan tres senadores por distrito, y México que asigna tres senadores por distrito más unos 32 senadores plurinominales en un distrito único nacional. Estados Unidos asigna un número de dos senadores por estado. No obstante, a pesar de que el criterio territorial es un criterio legítimo de representación del sistema federal, y en algunos casos se utiliza en sistemas unitarios con diferencias regionales (por ejemplo Bolivia), tiende a existir un ethos valorativo pro-igualitario del voto que hace más hincapié en el requisito democrático al cual supuestamente se ajustarían las cámaras bajas. 
De una muestra de 25 países bicamerales se puede obtener una idea de su situación representativa. La organización de los casos responde a un criterio medianamente plausible, que consiste en considerar el promedio de sobre-representación distrital (SRD) del total de sus legislaturas. Esto es, calcular los valores de SRD de cada cámara, ${ }^{13}$ sumarlos y dividirlos por dos. El cuadro 1 revela que Argentina es el sistema bicameral que más se desvía

\section{Cuadro 1}

Sobre-representación distrital en 25 países bicamerales

\begin{tabular}{|c|c|c|c|}
\hline País & $\begin{array}{c}\text { SRD } \\
\text { Cámara Baja }\end{array}$ & $\begin{array}{c}\text { SRD } \\
\text { Cámara Alta }\end{array}$ & Promedio \\
\hline Argentina (1997) & 16.28 & 49.73 & 33.00 \\
\hline España (2000) & 9.63 & 45.93 & 27.78 \\
\hline Bolivia (1997) & 17.00 & 38.00 & 27.50 \\
\hline Chile (1997) & 15.10 & 37.30 & 26.20 \\
\hline Brasil (1998) & 10.44 & 41.74 & 26.09 \\
\hline República Dominicana (1986) & 7.93 & 38.00 & 22.97 \\
\hline Venezuela (1998) & 5.37 & 32.65 & 19.01 \\
\hline EEUU (1992) & 1.44 & 36.42 & 18.93 \\
\hline Rusia (1995) & 3.82 & 33.46 & 18.64 \\
\hline Suiza (1995) & 1.93 & 34.48 & 18.20 \\
\hline Australia (1996) & 2.42 & 29.62 & 16.02 \\
\hline México (2000) & 1.56 & 27.29 & 14.42 \\
\hline Alemania (1994) & 3.44 & 24.40 & 13.92 \\
\hline Sudáfrica (1995) & 3.42 & 22.61 & 13.02 \\
\hline Polonia (1997) & 1.74 & 20.00 & 10.87 \\
\hline India (1991) & 6.22 & 10.79 & 8.50 \\
\hline Japón (1995) & 4.62 & 12.24 & 8.43 \\
\hline Colombia (2002) & 12.91 & 0.00 & 6.62 \\
\hline Rumania (1996) & 4.47 & 5.92 & 5.20 \\
\hline Austria (1994) & 6.43 & 3.01 & 4.72 \\
\hline República Checa (1996) & 2.71 & 2.57 & 2.64 \\
\hline Paraguay (1993) & 4.05 & 0.00 & 2.03 \\
\hline Italia (1996) & 0.82 & 2.92 & 1.87 \\
\hline Uruguay (1992) & 3.38 & 0.00 & 1.69 \\
\hline Holanda (1996) & 0.00 & 0.00 & 0.00 \\
\hline
\end{tabular}

Fuente: Elaboración y cálculos de promedios propia con base en datos de Samuels y Snyder (2001) para los casos no latinoamericanos, y para los casos latinoamericanos y España Reynoso (2002).

${ }^{13}$ El indicador de SRD para cada país se obtiene aplicando el cálculo del índice de desproporcionalidad de Loosemore y Hanby (1971), con una pequeña variante: en lugar de establecer la diferencia entre votos y escaños de los partidos, se calcula la diferencia entre el porcentaje de electores de un distrito y el porcentaje de escaños que se eligen en el mismo:

$$
S R D=\frac{1}{2} \sum|\% P-\% E|
$$

El índice de SRD consiste en sumar las diferencias absolutas existentes entre el porcentaje de población y el porcentaje de escaños de cada distrito. A esta suma se la divide 
del criterio demo-orientado, o mejor dicho es el país con mayor nivel de SRD, con un promedio de 33.00, seguido de España, Bolivia, Chile y Brasil. En contraste, el país que satisface matemáticamente el principio de 'una persona, un voto', o el país perfectamente ajustado al criterio demo-orientado de distribución de escaños, es Holanda (federal), mientras que Uruguay, Italia y Paraguay le siguen en esa escala de ajuste al ideal normativo.

De los 25 países, 19 de ellos poseen más SRD en sus cámaras altas que en sus cámaras bajas, mientras que de los seis restantes, cuatro de ellos no poseen cámaras altas con sobre-representación distrital (Colombia, Paraguay, Uruguay y Holanda). De esos seis países, cinco tienen cámaras bajas con más valor de SRD que sus cámaras altas (Colombia, Austria, República Checa, Paraguay y Uruguay), lo que va contra la noción de cámara de representación territorial, mientras que Holanda no posee sobre-representación distrital en ninguna de sus dos cámaras. Los sistemas bicamerales parecen seguir la lógica intuitiva: una cámara territorial y otra cámara en la cual la representación de los ciudadanos tiende a aproximarse al criterio demo-orientado, pues 19 de los 25 países presentan esa tendencia.

La figura 1 presenta tres tendencias empíricas de sistemas de representación en 25 países, todos ellos bicamerales. El criterio de diferenciación es arbitrario, pero considerando los límites matemáticos que suele imponer la división distrital, podemos conjeturar que un mínimo nivel de SRD no es producto de una decisión deliberada de introducir una compensación en favor de algunas sub-unidades o distritos electorales, sino debido a una imposibilidad matemática de fragmentar la representación (en sistemas de distritos plurinominales) o de construir distritos con un número equivalente de población, es decir, una imposibilidad físico-geográfica (en sistemas de distritos uninominales).

Comparativamente, podemos observar que la composición de la cámara alta en la mayoría de los sistemas federales responde a un criterio territorial, observándose sólo dos excepciones que están a la izquierda de la línea vertical (Austria y Holanda). Holanda constituye un tipo contra-intuitivo de federalismo al no incorporar ningún tipo de criterio territorial de representación. Si consideramos las cámaras bajas, resalta a simple vista que los

por dos para evitar la doble contabilización de las disparidades. La ventaja de este índice radica en que pueden contabilizarse todas las diferencias de representación encontradas en el sistema y reunirlas bajo un mismo indicador y así compararlos con otros sistemas. 


\section{Figura 1}

Tres tendencias de la sobre-representación distrital en países bicamerales

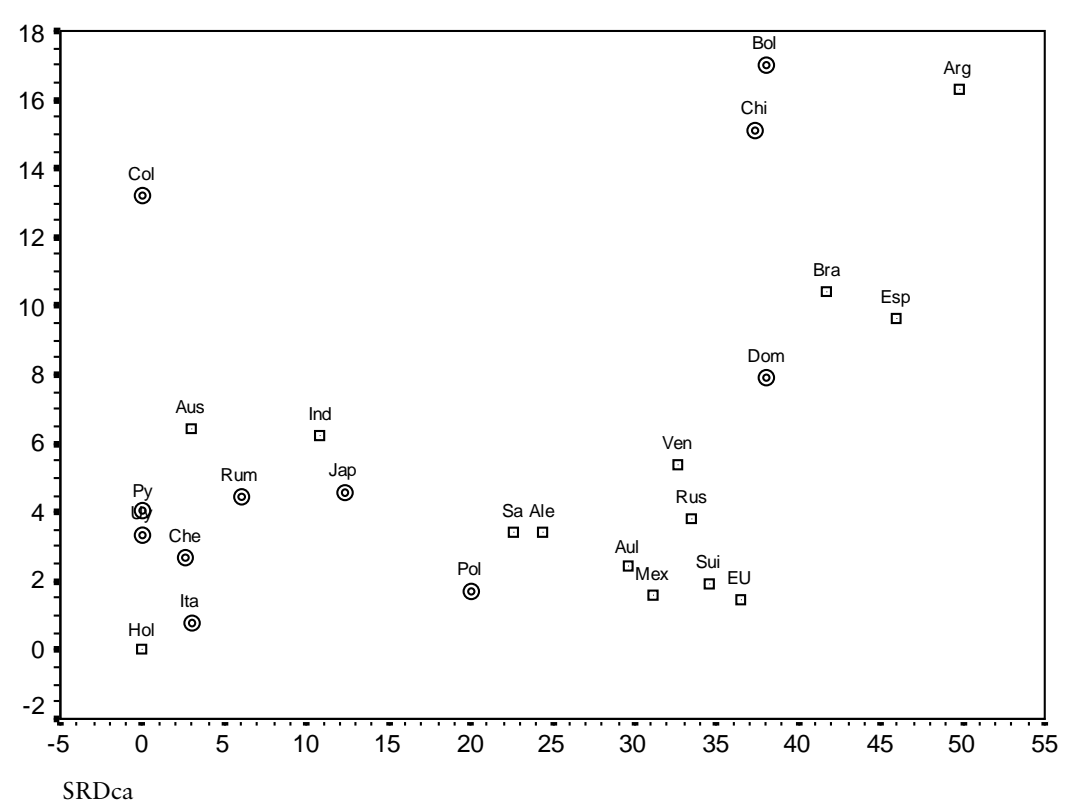

Fuente: Elaboración propia.

sistemas federales tienden a satisfacer el criterio demo-orientado, con la excepción de Argentina, Brasil y España, y en menor medida, Austria e India. La línea vertical divisoria de la gráfica es arbitraria, de este modo Austria fue incluida al conjunto del principio 'una persona, un voto' debido a que es apenas unos decimales superiores, mientras que India fue excluida de ese conjunto.

Existen tres tendencias claras representadas por los conjuntos, en cuanto a tipos de sistemas de representación según, como se combinan los niveles de SRD de ambas cámaras. Además, se encuentran tres casos residuales que pueden ser reagrupados en alguno de los tres conjuntos empíricos, con excepción de Colombia (en el margen superior izquierdo de la figura 1). Uno de los conjuntos está compuesto por los tipos demo-orientados de representación, que reúne a los sistemas que no poseen una pauta territorial en ninguna de sus cámaras, o que al menos admiten una pequeña distorsión que bien puede ser matemática pero no política. Las otras dos tendencias incluyen en alguna medida una pauta territorial, siendo los tipos federales los que la destinan a la cámara alta, mientras que los tipos identificados como terra- 
orientados presentan criterios fuertemente territoriales en ambas cámaras, lo que supone altos niveles de SRD.

Sistemas demo-orientados. El primer tipo de sistemas está compuesto por los países cuyas cámaras están dentro del área de satisfacción del principio de 'una persona, un voto' (el cuadrante inferior-izquierdo de la figura 1). Uruguay, Paraguay y Holanda poseen cámaras altas sin sobre-representación distrital, debido a sus sistemas de únicos distritos. El caso de Holanda es bastante atípico, puesto que si bien es un país federal, no contempla criterios de representación territorial en ninguna cámara. También ingresan a este grupo los casos de Italia, República Checa y Rumania. Este tipo de sistemas parece ser el más adoptado en los sistemas unitarios bicamerales y de extensión territorial pequeña. Por aproximación, Austria cabe ser incluida en este conjunto de sistema demo-orientados.

Tendencia federal. El segundo tipo de sistemas está compuesto por países que siguen una pauta de representación federal (cuadrante inferior-derecho de la figura 1). Todos los países de este segmento poseen cámaras bajas demo-orientadas y cámaras altas terra-orientadas. La lógica aquí parece ser la complementariedad de criterios representativos que dan lugar a una forma de bicameralismo incongruente (Lijphart, 1999) y con potencial de asimetría. Todos los países de este conjunto son federales, con excepción de Polonia. En todos estos casos la SRD en cámara alta es superior a 20.00 puntos, aproximadamente. Japón podría incluirse dentro de este conjunto, aunque su cámara alta sólo supere los 10.00 puntos, además de no ser un país federal. Invariablemente todos estos países poseen cámaras bajas con valores de SRD inferiores a la línea divisoria horizontal de 6.00 puntos. Ello parece ilustrar una tendencia de doble representación, o complementariedad de criterios representativos, muy típica del formato federal (Tsebelis y Money, 1999). Por un lado, una representación territorial en cámaras altas; por el otro, una representación adecuada al principio de 'una persona, un voto' en las cámaras bajas. Por un lado, una representación territorial en cámaras altas; por el otro, una representación adecuada al principio de 'una persona, un voto' en las cámaras bajas.

Sistemas terra-orientados. El tercer tipo de sistemas es el que denomino terra-orientados (cuadrante superior derecho de la figura 1) y está constituido por países con sobre-representación distrital en ambas cámaras que superan las líneas divisorias de la sobre-representación no intencionada. Argentina, Bolivia y Chi- 
le son los sistemas cuyos niveles de SRD indican un pronunciado predominio territorial de la organización de la representación. Viéndolo desde otro punto de vista, son los países más alejados del principio de 'una persona, un voto'. Dentro de esta tendencia se incluye a España, Brasil y República Dominicana. India es el otro país federal que podría ingresar a la zona de predominio territorial, aunque por sus valores de SRD se encuentra muy cercano a las dos líneas divisorias, haciendo francamente imposible determinar la intencionalidad del sesgo. Austria también posee esta característica de cercanía a los límites, pero sus relativamente bajos niveles de SRD en cámara alta alejan a este país de la tendencia fuertemente territorial. ${ }^{14}$

\section{Representación, territorio y democracia}

Latinoamérica presenta, en términos generales, un promedio de sobre-representación distrital elevado (Samuels y Snyder, 2001). Pero no hay una tendencia marcada que indique que existe un patrón predominante de sistemas de representación. Por el contrario, en la región tenemos un mapa variopinto de sobre-representación distrital bicameral. Los hay demo-orientados, los hay terra-orientados y también aquellos que se ajustan a la representación federal típica.

Si comparamos las cámaras bajas, solamente Perú posee un sistema sin sobre-representación distrital matemáticamente perfecto ${ }^{15}$ mientras México, Paraguay y Uruguay poseen sistemas que se ajustan políticamente al criterio demo-orientado de reparto de escaños, pero que debido a la división distrital se hace matemáticamente imposible fraccionar la representación, lo que produce la admisión de valores mínimos. Los que elevan el promedio de la región son los sistemas terra-orientados, entre los que figuran Argentina, Bolivia, Chile, y República Dominicana, a los que cabría agregar Ecuador y Colombia.

Hay que enfatizar que la implantación de la sobre-representación distrital da como resultado una mayor inclusión de partidos en la legislatura, allí donde la nacionalización del sistema de partidos es débil y cobran fuerza expresiones políticas locales,

\footnotetext{
${ }^{14}$ Ecuador presenta un alto nivel de SRD (aproximadamente 24\%), pero se trata de un sistema unicameral que no viene al caso comentar aquí.

15 También este caso se trata de un sistema unicameral.
} 
fundamentalmente aquellas localizadas en provincias o regiones sobre-representadas (Reynoso, 2002). ${ }^{16}$

Si se acepta que entre más número de partidos con representación, más repartido está el poder y mayor es la posibilidad y necesidad de ampliar el consenso, entonces la sobre-representación distrital introduce un efecto positivo al orientar al sistema electoral en una dirección más permisiva y más inclusiva. Por decirlo en otros términos, la probabilidad de compartir el poder entre más actores se incrementa (véase Lijphart, 1999). Por otra parte, además del incentivo al poder compartido, en países con una alta diversidad social, amplia extensión territorial o diversidad geográfica, la fuerte rivalidad entre el centro político y el interior o la periferia del país necesita de arreglos institucionales que la expresen. Este argumento resulta políticamente relevante. Por ejemplo, en Argentina es histórica la tensión existente entre el centralismo 'porteño' metropolitano y bonaerense frente al federalismo provincial fuertemente asentado en el interior del país. ${ }^{17}$ En este sentido, la sobre-representación distrital ha servido como una suerte de compensación entre las disparidades de poder existente, otorgando mayor representación a las provincias o distritos que no pertenecen al área metropolitana central. Además, la función de compensación en la cámara baja es aún más notable en los sistemas bicamerales donde el senado juega un papel residual. En virtud de que la cámara territorial no compensa el peso político de los diferentes territorios, se introducen criterios territoriales en la cámara baja, como tal parece ser el caso peculiar de Colombia.

Desde una perspectiva contraria, puede sostenerse que la diversidad de partidos que ingresan a la legislatura no es funcional a la necesidad de producir un gobierno eficaz. Desde este punto de vista, un mayor número de actores implica más problemas de coordinación, más costos internos en la toma de decisiones y potencialmente menos eficacia. Dado ese supuesto, la inclusión de muchos partidos en la legislatura produciría una mayor división y generaría obstáculos a un gobierno eficaz y dificultaría la formación de un gobierno unificado y eficaz. La necesidad de evitar la

\footnotetext{
${ }^{16}$ Una corrección a este argumento. La tendencia a presentar un número de partidos mayor no es generalizable a los sistemas uninominales o de magnitudes bajas constantes (como por ejemplo un sistema binominal). El efecto, en realidad, se produce al incrementar la magnitud de los distritos más chicos respecto de la magnitud que hubiesen recibido si se hubiesen distribuido los escaños conforme un criterio demoorientado.

${ }^{17}$ También en Brasil, España y Rusia, por citar solamente unos pocos ejemplos.
} 
fragmentación del sistema partidario legislativo implicaría la construcción y adopción de sistemas electorales más restrictivos (véase Jones, 1995). De esta suerte, una reducción de la sobre-representación distrital permitiría inclinar el mecanismo de conversión de votos en escaños en un sentido más restrictivo, al constreñir el ingreso de los partidos a la legislatura. Pero al mismo tiempo, permitiría que los distritos más poblados y urbanos con mayor magnitud de distrito, en donde los partidos nacionales tienen sus electorados, dominen la arena legislativa y la política nacional.

Esta segunda perspectiva, invariablemente, favorece la tendencia hacia una mayor centralización política, lo cual no parece deseable en países con una larga tradición de luchas por la disminución del poder central, que ha devenido en constituciones formalmente federales (por ejemplo Argentina, Brasil y México) o que en la práctica funcionan con una alta descentralización (por ejemplo Bolivia y Colombia), o que han logrado la unidad del Estado mediante el otorgamiento de un estatus especial a determinadas regiones o comunidades (por ejemplo España y Canadá).

En lo que se refiere al sistema de partidos y al funcionamiento de la legislatura, debe pensarse seriamente la cuestión sobre qué tipo de sistema electoral permite dirigirse en una $u$ otra dirección. Sin embargo, no parece factible que en Latinoamérica un sistema más restrictivo facilitaría o mejoraría simultáneamente la función representativa y la función de gobierno, sobre todo teniendo en cuenta las disparidades de los desarrollos regionales, la importancia de los gobiernos sub-nacionales y su impacto en la estabilidad democrática.

\section{Una conclusión tentativa}

Como algunos elementos de juicio parecen apoyar, en la mayoría de los casos muchos votos 'no contarían' si la distribución de los escaños se hiciera conforme al principio democrático 'una persona, un voto'. Esta es una de las grandes paradojas de la sobrerepresentación distrital: normativamente no posee suficientes credenciales de aceptabilidad democrática, pero funcionalmente pareciera hacer viable un orden político representativo territorialmente. Con el fin de lograr que los votos cuenten (parafraseando a Cox, 1997), resulta muchas veces imprescindible y hasta preferible. Este es el problema que la sobre-representación distrital resuelve satisfactoriamente en muchos sistemas políticos, y en ello reside su utilidad. Incluir más actores en la toma de decisio- 
nes, como por ejemplo sucede en los sistemas federales, contribuye a compensar ciertas disparidades regionales, étnicas, poblacionales o económicas. Ahora bien, desde una perspectiva estrictamente normativa no hay manera de justificar la sobre-representación, en tanto violación del principio democrático de 'una persona, un voto', sin que se debilite al mismo tiempo la legitimidad misma del resultado del proceso democrático (Dahl, 1989: 267). Si todas las personas son iguales y gozan de los mismos derechos, no parece existir ninguna justificación que permita tolerarlo. Sin embargo, parafraseando a Bobbio, hay una gran "diferencia entre los ideales democráticos y la democracia real" (Bobbio, 1984: 16). Y es que lejos de ser todos los individuos iguales, lo que corresponde a una imagen de la sociedad como un todo homogéneo, existen diferencias regionales, territoriales, sociales, lingüísticas, étnicas, etc., que indican que "la sociedad que subyace en los gobiernos democráticos es pluralista" (Bobbio, 1984: 18).

Las disparidades existentes en una sociedad empujan para ser tomadas en cuenta y, muchas veces, la satisfacción del principio de 'una persona, un voto' impide que las minorías sean escuchadas en el proceso de toma de decisiones. Por ello, cierto desvío del principio permite la sobre-representación distrital y una ponderación de los votos en ciertos territorios, o a determinados grupos sociales, lo cual genera un efecto de compensación política a través de la representación, que funciona como contrapeso a las desigualdades regionales o sociales, que puede contribuir a mejorar el funcionamiento y la calidad del régimen democrático.

\section{Bibliografía}

Balinski, Michel and H. P. Young (1983), Fair Representation: Meeting the Idea of One Man, One Vote, Yale University Press, New Haven.

Black, Duncan (1958), The Theory of Comitees and Elections, Cambridge University Press, Cambridge.

Bobbio, Norberto (1984), El futuro de la democracia, FCE, México.

Cox, Gary (1997), Making Votes Count: Strategic Coordination in the World's Electoral Systems, Cambridge University Press, Cambridge. 
Dahl, Robert (1971), Poliarchy, Yale University Press, USA.

Dahl, Robert (1989), La democracia y sus críticos, Paidós, Buenos Aires. [primera edición en español, 1991].

Elazar, Daniel (1987), Exploración del Federalismo, Editorial Hacer, Barcelona [primera edición en español 1990].

Elster, Jon (1988), Constitucionalismo y Democracia, FCE, México [primera edición en español, 1999].

Fossas, Enric y Ferran Requejo (1999), Asimetría Federal y Estado Plurinacional: El debate sobre la acomodación de la diversidad en Canadá, Bélgica y España, Trotta, Madrid.

Jones, Mark (1995), Electoral Laws and the Survival of Presidential Democracies, University of Notre Dame Press, UsA.

Kymlica, Will (1996), Ciudadanía multicultural: una teoría liberal de las minorías, Paidós, Barcelona.

Lijphart, Arend (1999): Patterns of Democracy. Government For$m s$ and Performance in Thirty-Six Countries, Yale University Press, New Haven.

Linz, Juan (1997), Democracy, Multinationalism and Federalism, Working Paper 1997/103, Instituto Juan March, Madrid.

Loosemore, John y Victor Hanby (1971): “The Theoretical Limits of Maximun Distortion: Some Analytic Expressions for Electoral Systems" en British Journal of Political Science, 1, pp.467-77.

Mainwaring, Scott y Mark Jones (2003), "La nacionalización de los partidos y los sistemas de partido", Politica y Gobierno, vol. x, núm.1, CIDE, México.

Monroe, Burt (1995), "Fully Proportional Representation”, American Political Science Review, vol. 89, núm.4, diciembre.

Naciones Unidas (2003), Declaración Universal de los Derechos Humanos, Adoptada y proclamada por la Resolución de la 
Asamblea General 217 A (iii) del 10 de diciembre de 1948, en <http://www.un.org/spanish/aboutun/hrights.htm> agosto del 2003.

Reynoso, Diego (2002), "Las consecuencias políticas de la sobrerepresentación distrital" en Política y Gobierno, vol. IX núm. 2 CIDE, México.

Samuels, David y Richard Snyder (2001), "Devaluing the vote: Latin America's Unfair Election", Journal of Democracy, vol. 12 núm.1, pp. 146-159.

Sartori, Giovanni (1992), Elementos de teoría política, Alianza Universidad, Buenos Aires.

Sen, Amartya (1970), Colective Choice and Social Welfare, Holden Day, San Francisco.

Stepan, Alfred (1999), "Federalism and Democracy: Beyond the us Model", Journal of Democracy, vol. 10, núm. 4, pp. 19-34.

Tsebelis, George y Jeannette Money (1999), Bicameralism, Cambridge University Press, Cambridge.

Enviado: 7 de agosto de 2003. Aceptado: 4 de noviembre de 2003. 